\title{
Profile of Student's Mathematical Representation Translation on the Verbal Problem
}

\author{
Nizaruddin", St. Budi Waluyo, Rochmad, Isnarto \\ Department of Mathematics Education, Postgraduate Program, Universitas Negeri Semarang, Semarang, Indonesia
}

Received October 18, 2020; Revised November 24, 2020; Accepted December 20, 2020

\section{Cite This Paper in the following Citation Styles}

(a): [1] Nizaruddin, St. Budi Waluyo, Rochmad, Isnarto, "Profile of Student's Mathematical Representation Translation on the Verbal Problem," Universal Journal of Educational Research, Vol. 8, No. 12B, pp. 8178-8185, 2020. DOI: 10.13189/ujer.2020.082621.

(b): Nizaruddin, St. Budi Waluyo, Rochmad, Isnarto (2020). Profile of Student's Mathematical Representation Translation on the Verbal Problem. Universal Journal of Educational Research, 8(12B), 8178-8185. DOI: 10.13189/ujer.2020.082621.

Copyright $\odot 2020$ by authors, all rights reserved. Authors agree that this article remains permanently open access under the terms of the Creative Commons Attribution License 4.0 International License

\begin{abstract}
Translation among forms of representation defines as changing process one form of representation to other representations. Translation activities from one representation (source) to another (target) are very important in expressing mathematical ideas. In translating among representations, students are not only interacting with the basic concepts contained in the information, but also they must be able to connect parts of these basic concepts with different things related to the intended representation. The purpose of this qualitative research is: 1) to analyze the tendency of mathematical representations to be used in solving mathematical problems given in verbal representations, and 2) to analyze the translational structure of the target representations made. The research subjects were $3^{\text {rd }}$ year students of Mathematics Education at Universitas PGRI Semarang. The research data were taken by means of tests and interviews immediately after solving the math problems given in the form of verbal representations. The results showed that the group students who were solving the verbal questions indicated that they tended to translate from the verbal representations to symbolic representations in presenting definitions and in proof. However, this symbolic representation still contained verbal representations such as in the source problems. The stages of representation in this research followed the translation stages: unpacking the source, preliminary coordination, constructing the target, but left for determinant of equivalence. High-ability group of students in solving the questions tend to translate from verbal representation to symbolic representation. Further, some of them translate verbal to visual representation to
\end{abstract}

increase understanding. The translation stages are unpacking the source, preliminary coordination, constructing symbol representation, constructing visual representation, determining the equivalence of the visual representation to verbal representation, and determining the equivalence of the symbol representation form to verbal representation.

Keywords Symbol Representation, Translation, Verbal Representation, Visual Representation

\section{Introduction}

Representation is creativity that involves expressing or exposing someone's ideas to present mathematical answers or ideas for their work [1][2][3]. Operationally, Pape \& Tchoshanov [4] explain that representation can be described in at least four main ideas, namely: 1) representation as an enclosed contemplation of mathematical notions or cognitive formation composed by pupil over practices; 2) representation as thoughtful replication of proceeding thoughtful states; 3) representation as representations of structure equivalence through pictures, symbols or symbols; and 4) representation as knowledge about something that represents something else

The importance of representation in mathematics learning has been widely studied, such as studies conducted by Amit \& Fried [5], Elia [6], Gagatsis \& Elia 
[7], Harries \& Barmby [8], Hwang et al. [9], Kalathil \& Sherin [10], Michaelidou et al. [11]. Kalathil \& Sherin [10] stated that there are three external representation functions produced by students in learning mathematics: 1) representation as a means for a person's way of thinking about a mathematical idea or idea to others, 2) representation as a way of showing the tendency of work patterns among students, and 3) representation as a tool in the learning process by teachers and students. Second opinion about representation is that representation plays a significant role in understanding mathematical concepts, namely by interpreting representations as a tool in representing mathematical ideas $[8][11][12]$. This is in accordance with the results obtained by Gagatsis \& Elia [7], Michaelidou et al. [11]. Another opinion is expressed by Harries \& Barmby [8] that mathematics is accepted if its thougtful representations are element of a structure of portrayels.

In learning mathematics, Hwang et al. [9] divide the representations toward five catagories, including portrayels of actual phenomenon, concrete portrayels, arithmetic badge representations, spoken or rhetorical language portrayels, and ocular or graphic portrayels. Furthermore, it is said by Kaput [13], Lesh [14], and Milrad [15] that in learning representations for solving mathematical problems, there are three levels that are higher and abstract: 1) language representation skills, namely the skills to translate the properties of observations and the relationship of mathematical problems in verbal or vocal representations, 2) image or graphic representation skills, namely the ability to translate mathematical problems into image or graphic representations, 3) arithmetic symbol representation skills, namely the skills to translate mathematical problems into the arithmetic formula representation.

Someone in conveying a mathematical answer or idea sometimes has to use a variety of representations so that the recipient of the idea can receive it well, likewise when understanding a mathematical idea, someone sometimes requires a variety of representations. The use of a concept or procedure representation in more than one format is said to provide multiple representations of knowledge [16][17]. The use of multiple representations in learning is build on the belief that tutoring with multiple portrayels ease and enhance the learning alter by adding multiple causes of reference data [18][19][20]. Another important role of multiple representations in mathematics learning is also conveyed by Cai \& Lester [21] especially in helping to understand and interpret mathematical concepts in various representations.

The need to use various mathematical representations to express a mathematical idea does not rule out the possibility that students have to adjust a form portrayels to another form ofportrayels albelled translation among forms of representation [7]. Translation among forms of representation is a process that occurs in representation.
Janvier [22] explains that translation among forms of representation is a process of changing one form of representation to other, for example translating from symbol to visual form. In changing one representation to other representation, it takes the ability to define, identify, manipulate and construct the source representation into the target representation. In solving problems, a student is required to be able to translate between the representations of the problems properly, so that the representation produced in solving the problem is as desired. Duval [23] states that the activities of translation activities from one representation to another are very important in the learning process. The treatment of assorted category of representations, and translations among portrayels is really critical in expressing mathematical concept [24].

In translating among representations, students are not only interact with the basic concepts contained in the information, but also they must be able to connect parts of these basic concepts with different things related to the intended representation. This is because the process of making representations involves identifying, selecting and conveying ideas through something else [25]. This is in line with the opinion of Bosse et al. [26] that someone who translates has to not only know or recognize the concept contained in the source by identifying and coding, but also can connect the concept into different forms according to the intended representation or target representation. Research on representation translation conducted by Bosse, et al. [26] revealed that students of different levels of representation ability use different strategies both in preliminary coordination and in building targets. Research by Molina et al. [27] focuses on the analysis of translation errors of symbolic representations and verbal representations on algebraic material in 2nd and 4th year high school students, it is found that students from both groups experience more errors when the statement is not an equation. Research on representation translation conducted by Rahmawati et al. [28] shows that there are 3 types of translation of verbal representations to visual, namely translation of verbal representations to visual through symbolic representations, translation of verbal representations to graphs through numerical representations, and translation of verbal representations to visual without going through the intermediary of other representations. Another research stated that in changing the verbal representation to the symbol representation it was found that new students were able to complete the unpacking stage of the source, but students were not able to carry out the next translation stages, namely preliminary coordination, constructing the target, and determining equivalence completely [29].

The purpose of this research is: 1) to analyze the tendency of mathematical representations to be used to analyze the tendency of the choice of mathematical representations to be used in solving mathematical problems in the form of verbal representations, and 2) to 
analyze the translational structure of the target representations made and the translational structure of mathematical representations by prospective mathematics teacher in the process of identification, selection and delivery of ideas in forming new representations.

\section{Materials and Methods}

This research is a descriptive qualitative which describes the tendency of students' translation in mathematical representations. The subjects of this research were 26 students who were divided into 6 discussion groups in the introductory real analysis lecture at Universitas PGRI Semarang. The research implementation begins with the activity of working on student task sheet in groups of 3-4 people so that students get various information from their group members on real number sequence material from the source book 'Introduction to Real Analysis' by Bartle \& Sherbert [30]. The next stage is a class discussion with the lecturer providing definitions and theorems in verbal representations through question and answer, then continued with exercises to prove problems in groups of 3-4. These problems support the development of understanding definitions and theorems as well as the construction of students' knowledge to practice constructing different representations.

Data were collected using tests and interviews. Before being used for data retrieval, all instruments have been validated and declared fit for use. The test instruments in this research were as follows:

"A sequence $X=\left(x_{n}\right)$ in $\mathbf{R}$ is said converge to $x \in \mathbf{R}$, or $\mathrm{x}$ is said to be a limit of $\left(\mathrm{x}_{\mathrm{n}}\right)$, if for every $\varepsilon>0$ there exist a natural number $K(\varepsilon)$ such that for all $n \geq$ $\mathrm{K}(\varepsilon)$, the terms $\mathrm{x}_{\mathrm{n}}$ satisfy $\left|\mathrm{x}_{\mathrm{n}}-\mathrm{X}\right|<\varepsilon$ ".

The problems given are:

1. Write the definition of the limit for a real number sequence in symbolic or graphic representation!

2. Let $X=\left(x_{n}\right)=((2 n+3) / n)$ is a sequence of real number. Determine the limit, and prove it!

Two student work results are described in this article (subject $\mathrm{M}$ and subject $\mathrm{H}$ ). The two results of this work represent the answers of other subjects, namely the answers of eight low-ability students and the answers of ten medium-ability students who show the same results. Meanwhile, eight answers from highly skilled students have been able to translate from verbal representations to symbolic representations and visual representations to answer research problems. Selection of research subjects by paying attention to students' work and their communication skills. To obtain data credibility, source triangulation technique is used, namely by comparing the results of the subject's work in the same ability category. The researcher acts as the central instrument that acts to collect data, analyze and interpret data, and report results. Data analysis was performed by data reduction, data display, and drawing conclusions or verification. The translation process carried out by students in changing the form of representation is seen from the steps carried out based on the translation stages of unloading the source, preparatory planning, building up the target, and resolving equivalence [26].

\section{Results and Discussion}

This research analyzes the tendency of mathematical representations built for real number sequence material through the answers to the problems given. The research subjects were given problems which were presented in verbal form. Subjects were asked to translate from verbal mathematical representations to other representations. In general, to observe a different representation from the source representation is by seeing the tendency of the target representation aimed by students. The answer to question no.1 is intended to analyze the tendency of representations made and whether the schema of real number sequences is thematic and coherent and also to explore the stages of translation from one form of representation to another. The answer to question no. 2 is to reveal the tendency of the form of representation used and problem solving activities and the depth of using the selected representation. The scheme used in solving problem 2 is supported by the scheme for determining the limit value and the scheme for defining the real number limit according to the representation chosen to solve this problem. The selection of this proving question is to see math mastery and the ability to elaborate on existing information to see the stages of translation. Moreover, students must have the ability to build mathematical evidence [31][32]. Several studies have stated that almost everyone has experienced difficulties in doing proof, including students [33][34][35][36].

\subsection{Mathematical Representation of Moderate Ability Subjects (M)}

In solving question 1 , all of moderate subjects (M) use symbolic representations, but in describing symbols, they do not fully understand. For example, students do not understand that the symbol $\varepsilon$ is an arbitrary real number. However, the symbol representation made still contains a verbal representation such as in the problem given (source). This can be seen as written by subject $\mathrm{M}$ below.

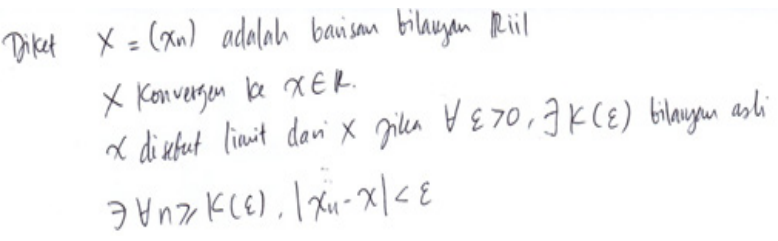

Figure 1. Answer Problem No. 1 by Subject M

Figure 1 shows that the subject $M$ has been able to 
write the definition of the limit of the sequence with the symbol representation. In this type of answer, there is still the use of verbal representations that could be symbolized. Furthermore, when student is asked to make representations of real numbers that are not the limit value of a series of real numbers, subject $\mathrm{M}$ has not been able to deliver it completely. The interview quotation shows the tendency of representation and the ability to use symbols that are lacking in the subject $\mathrm{M}$.

Interviewer:Is this really the definition of sequence limit?

Subject M: Yes, sir.

Interviewer: This is different from the one given above, what form do you present this?

Subject M: This means the same, sir, I present it in mathematical symbols.

Interviewer: Ok. Why did you make symbols? Is there no other way of presenting to explain?

Subject M: Actually there are, with pictures, but I'm confused.

Interviewer: There is still a sentence, is there no symbol?

Subject M: I forgot, sir.

Interviewer: Now give an example of the limit value of a sequence that you are familiar with when discussing the definition of a real number sequence.

Subject M: Sequence $X=(1 / \mathrm{n})$, with limit value 0 .

Interviewer: 1 is the limit value, right? If so, why? If not, why?

Subject M: No, it's not. It is 0 .

Interviewer: Can you explain why 1 is not the limit value using the definition of the limit value.

Subject M: I don't know.

Looking from the Bosse et al. [26] stage: the first activity is unpacking the source. After reading the problem, subject $\mathrm{M}$ knows the words related to the initial information on the problem. This shows that the subject is able to unload information well. It can be seen that when he unpacking the two problems, the subject knows that $x_{n}$ is a real number and knows that it is asked to present it in mathematical symbols. In uncovering question 1, students can explain related words verbally. Furthermore, in the preliminary coordination stage, students can predict the representation that will be made based on the available information. At this stage the subject states that what comes to mind is to make it as it is usually accepted in other courses, namely always using symbols in mathematics. Here is the following interview results.

Interviewer: Oke, you already know what is given and what is asked from the question no 1. Is that right?

Subject M: Yes sir.

Interviewer: What was asked.

Subject M: Present as symbols or pictures.

Interviewer: Then what will you do?

Subject M: I chose to make it in a symbol.

Interviewer: You can not choose though, you have to do both.

Subject M: Sorry Sir, I can't imagine what the picture looks like? Symbol is usually used in other materials, but in solving the problem it is always use symbol.

Interviewer: So you can't imagine the picture or because it's usually a symbol?

Subject M: Both of them.

At the constructing the target stage, students began to make symbolic representations but some words were still used. The subject explained that the use of words was so easy to understand, but it was also found that this happened because the subject did not master the symbols of these words.

In solving question number 2, subject $\mathrm{M}$ uses symbolic representations to get the limit value by deciphering the formula of the sequence as shown in the Figure 2. The subject did not try to represent the image, and based on the interview the subject was unable to illustrate in the image representation.

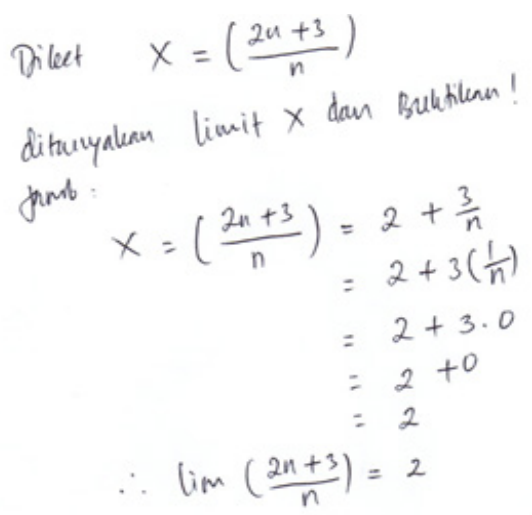

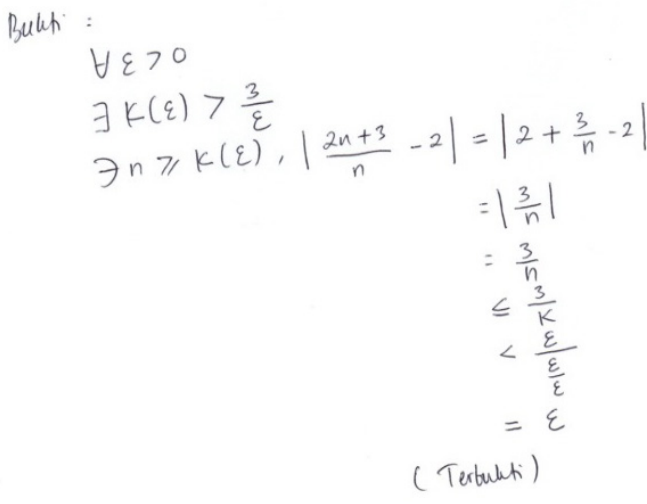

Figure 2. Answer Problem No. 2 by Subject M 
Interviewer: Did you find the limit value claim?

Subject M: Yes sir, it is 2 .

Interviewer: I see this is described, what is the reason?

Subject M: Because during lecture I was told the limit value $(1 / \mathrm{n})=0$, so I just made it like that.

Interviewer: If I ask for an illustration in a picture, how about it?

Subject M: Use a number line Sir, but I'm confused.

Interviewer: Do you know the meaning of limit value?

Subject M: I know it, .... that meets definition.

Interviewer: Can it be presented in everyday words.

Subject M: I'm confused sir.

Subject M appears to be able to use symbols to unpack information from question no. 2 , so that he can decipher $(2 \mathrm{n}+3) / \mathrm{n}=2+3 / \mathrm{n}=2+3(1 / \mathrm{n}), \mathrm{n}$ natural numbers. Hence, he can find the limit value of the ranks given. However, it appears that subject failed in proving. Subject picked number in certain cases that should have been the general case. This is related to the difficulty of students in starting proof [37]. The results of the interview showed that the students understood the lecture material but there was confusion when using it in proving it. In line with the interview, students only applied the definition in symbolic representation but did not fully understand the meaning of the limit value. They could not make an image representation. Students also do not know the meaning of finding the original number $\mathrm{K}$ for each $\varepsilon$.

Interviewer: Have you found the natural number $\mathrm{K}(\varepsilon)$ in your proof?

Subject M: K> $3 / \varepsilon$

Interviewer: How if I change $\mathrm{K}>5 / \varepsilon$

Subject M: Don't know, sir. K> $3 / \varepsilon$

It appears that subject $M$ is able to find the $K$ value but does not master the use of the $\mathrm{K}$ value in the given definition. In the in-depth research, it was also found that the subject was still confused when the $\varepsilon$ value was replaced by a different number

\subsection{Mathematical Representations of High Ability Subjects (H)}

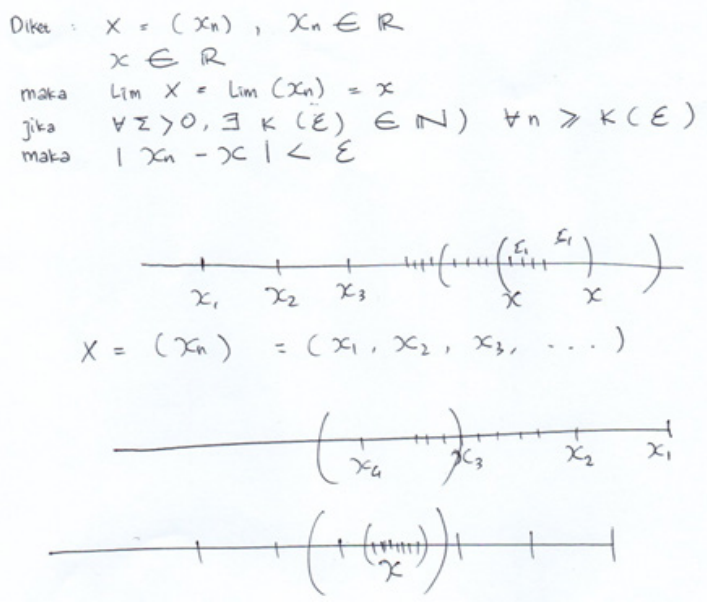

Figure 3. Answer Problem No. 1 by Subject $\mathrm{H}$
Subject $\mathrm{H}$ presents the definition of the limit of real numbers with mathematical symbols and language correctly. However, in describing the symbol there is a lack of understanding. For example, the symbol $\varepsilon$ is not interpreted as any real number. Students can also make a simple picture representation of the definition (see Figure 3).

In the interview, he can also give examples of real numbers which are not the limit value of the given sequence. However, he has not been able to prove why the real number is not the limit value. Here is the interview excerpt when subject $\mathrm{H}$ asked to give examples of different sequences and show a real number that is not the limit. In this case the subject $\mathrm{H}$ sees by comparing what he already knows the limit value, not based on the inverse of the definition of the limit for real numbers.

Interviewer: Make examples of other sequence besides the one you created earlier.

Subject H: $\mathrm{X}=(1+1 / \mathrm{n})$, with $\mathrm{n}$ natural numbers

Interviewer: What number is not the limit?

Subject H: 0

Interviewer: Why?

Subject H: The limit value of $1 / \mathrm{n}$

Interviewer: What do you mean?

Subject H: So the limit cannot be 0 , because that's $1+1$ $/ \mathrm{n}$.

In translation of representation, the first stage is unpacking the source. subject $\mathrm{H}$ knew well the initial informational words of the problem. In other words, the subject is able to decipher information well. It can be seen that when unpacking the two problems, the subject knows that $x_{n}$ is a real number and knows that it is asked to present it in mathematical symbols. In uncovering problem 1, students can explain the existing information verbally and also accompanied by pictures. At the preliminary coordination stage, students can estimate the representation that will be carried out along with the steps, namely the representation of symbols and images. At this stage the subject states that the first will make symbol representations as commonly accepted in other courses by using symbols in mathematics and will be accompanied by images to clarify the meaning of the symbol representations made. As the following interview results.

Interviewer: Do you understand the meaning of the definition of the limit of real numbers given?

Subject H: A little sir.

Interviewer: Why?

Subject H: Because we use words.

Interviewer: What was asked

Subject H: Present as symbols or pictures

Interviewer: Then what will you do?

Subject H: I'll make it in symbols first.

Interviewer: Why?

Subject H: Because it's just a matter of replacing the sentence and also the symbols are usually used in other materials and if you solve a problem, it's always symbolic. 
Interviewer: How about drawing pictures?

Subject H: For this, I want to see the symbol first, then I draw a picture to better understand it.

Interviewer: Returning to the symbol, the symbol may or may not define a real number instead of the limit value of a sequence.

Subject H: Yes, sir. It remains only to write down the opposite of the symbol.

Interviewer: Can you put it into words?

Subject H: Yes, I can.

Interviewer: Try to write down the symbol representation.

Subject H: Yes, I can.

It can be seen in Figure 4 that at the constructing the target stage, students began to replace some words with language and mathematical symbol representations. Subject $\mathrm{H}$ can also write the cons of the symbol and present it in words so that it can know the initial meaning of the definition of a real number, not the limit value of a sequence. Furthermore, together with forming the symbol representation it also forms an image representation. Through repeated observations between symbolic representations and visual representations made by comparing their suitability with the problems presented in verbal representations, subject $\mathrm{H}$ has performed determining equivalence by prioritizing the form of visual representation followed by symbol representation.

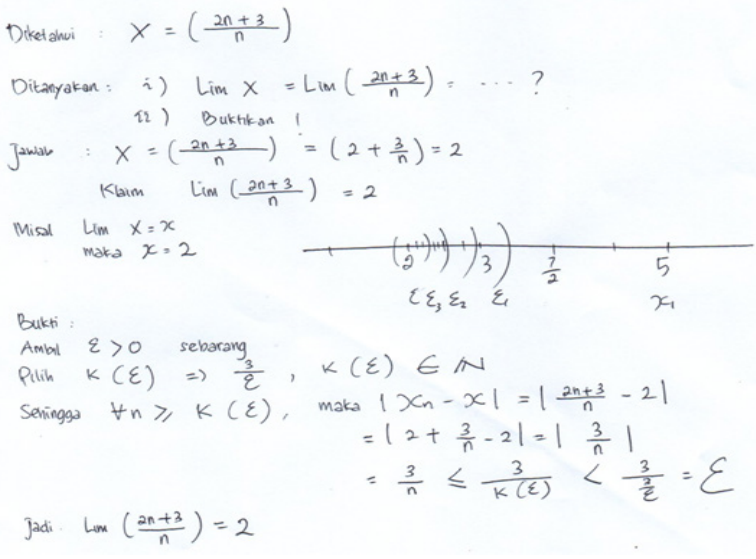

Figure 4. Answer Problem No. 2 by Subject $\mathrm{H}$

Subject $\mathrm{H}$ solved Question no. 2 by using symbolic representations to get the limit value without describing the formula in detail from the sequence as in the Figure 5. The subject also performs visual representations and based on the interview students can explain the visual representations that are made simply.

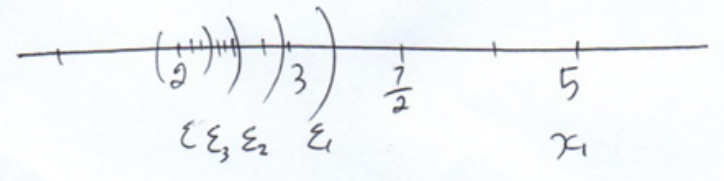

Figure 5. Symbolic Representation
Interviewer : Did you find the limit value claim?

Subject H : Yes sir, 2.

Interviewer : I see. This is described, what is the reason?

Subject $\mathrm{H}$ : Example from lecture: the limit value (1 / $\mathrm{n})=0$, so $3(1 / \mathrm{n})$ the limit value is also 0

Interviewer : What does the picture mean?

Subject H : On a number line, this is the sequence of the numbers and the sequence gets up to the number 2

Interviewer : What does it mean?

Subject $\mathrm{H}$ : It means that the sequence will gather around 2 .

It can be seen from the picture that that subject $\mathrm{H}$ can use symbols and pictures to unpack information from question no. 2, more simply $(2 \mathrm{n}+3) / \mathrm{n}=2+3 / \mathrm{n}, \mathrm{n}$ natural numbers, and find the limit value of the given sequence. In proving, they already understand universal numbers, but when asked to replace universal numbers with different real numbers, students are still confused. This relates to students' difficulties in logic and methods of proof [37].

Interviewer : Did you find the K value for every $\varepsilon$ ?

Subject $\mathrm{H} \quad$ : Yes sir, $\mathrm{K}>3 / \varepsilon$

Interviewer : If $\varepsilon=1 / 100$, in what order is the sequence $\mathrm{n}$ ?

Subject $\mathrm{H} \quad: 301,302,303$ and so on sir

Interviewer : If $\varepsilon=987965$, to what $n$ ?

Subject H : Later si. I'm confused.

The results of the interview showed that students understood the lecture material and could use it in proof with symbolic representations and visual representations. However, subjects $\mathrm{H}$ were unable to explain the meaning of symbols consistently. The use of symbolic representations tends to be used to fulfill the obligation to formally prove it.

\section{Conclusions}

The tendency of using representations in understanding definitions and in providing proof, as well as the structure of the translation of the form of representation carried out by dividing the results of problem solving into two groups, namely the medium and high groups are as follows: 1) Students with the classified into moderate show that they tend to translate from verbal representations to symbolic representations in presenting definitions and in proof, but still contain verbal representations such as the problems given. The translation stage of unpacking the source is seen when unpacking the two questions, the subject knows the information from the source well and knows he is asked to present it in the form of a symbol representation. At the preliminary coordination stage, students were able to estimate the target representation based on existing information and thought to make it with 
mathematical symbols. The constructing stage of the target has been carried out by forming a target representation but not doing the determining equivalence stage. The use of mathematical symbols is only to meet the standard of formality in proof. Subjects cannot make visual representations or images because they are unable to carry out the preliminary coordination stage, constructing the target in building a visual or image representation of the given questions. The stages carried out are in accordance with the translation stages of Bosse et al. [26], that is unloading the source, preparatory planning, building up the target, but not resolving equivalence. 2) High students in solving the given questions tend to translate from verbal representations to symbolic representations and use translation to visual representations or images to increase understanding. The steps taken in translating the form of representation are unloading the source, preparatory planning, building up the target, and resolving equivalence with unpacking the source modification, and preliminary coordination is carried out simultaneously in changing to the form of symbol and image representation, so that the translation stage that is passed is unpacking the source, preliminary coordination, constructing the target form of symbol representation, constructing the target form of image representation and determining equivalence of form of image representation and determining equivalence of symbol representation.

\section{REFERENCES}

[1] Murtianto, Y. H., Muhtarom, M., Nizaruddin, N., Suryaningsih, S. (2019). Exploring student's productive thinking in solving algebra problem. TEM Journal, 8(4), 1392-1397.

[2] Nizaruddin., Muhtarom, \& Murtianto, Y. H. (2017). Exploring of multi mathematical representation capability in problem solving on senior high school students. Problems of Education in the $21^{\text {st }}$ Century, 75(6), 591-598.

[3] Kalathil, R. R., \& Sherin, M. G. (2013). Role of students' representations in the mathematics classroom. In International Conference of the Learning Sciences: Facing the Challenges of Complex Real-world Settings. Psychology Press.

[4] Pape, S. J., \& Tchoshanov, M. A. (2001). The role of representation(s) in developing mathematical understanding. Theory into Practice, 40(2), 118-125.

[5] Amit, M \& Fried, M. N. (2005). Multiple representations In 8th grade algebra lessons: Are learners really getting It. In Chick, H. L. \& Vincent, J. L. (Eds.). Proceedings of the 29th Conference of the International Group for the Psychology of Mathematics Education, Vol. 2, pp. 57-64.

[6] Elia. (2004). Multiple representations in mathematical problem solving: Exploring sex differences.[Online].
Available:

http://prema.iacm.forth.gr/does/ws1/papers/iliada $\% 2$.

[7] Gagatsis, A., \& Elia, I. (2004). The effects of different modes representation on mathematical problem solving. In Proceedings of the $28^{\text {th }}$ Conference of the International Group for the Psychology of Mathematics Education. Norway: Bergen University College.

[8] Harries \& Barmby. (2006). Representing multiplication. Proceeding of the British Society for Research into Learning Mathematics, 26(3), 25 - 30.

[9] Hwang, W. Y., Chen, N. S., Dung, J. J., \& Yang, Y. L. (2007). Multiple representation skills and creativity effects on mathematical problem solving using a multimedia whiteboard system. Educational Technology \& Society, 10(2), 191-212.

[10] Kalathil, R.R., \& Sherin, M.G. (2000). Role of Students' Representations in the Mathematics Classroom. In B. Fishman \& S. O'Connor-Divelbiss (Eds.), Fourth International Conference of the Learning Sciences. Mahwah, NJ: Erlbaum.

[11] Michaelidou, N., Gagatsis, A., \& Pitta-Pantazi, D. (2004). The number line as a representation of decimal numbers: $A$ research with six grade students. International Group for the Psychology of Mathematics Education.

[12] Neria, D. \& Amit, M. (2004). Students preference of non algebraic representations in mathematical comunication. Proceding of the International Group for the Psychology of Mathematics Education, 3(27), 409-416.

[13] Kaput, J. (1989). Linking representations in the symbol systems of algebra. In S. Wagner \& C.Kieran (Eds.), Research issues in the teaching and learning of algebra. Reston, VA: NCTM.

[14] Lesh, R., Post, T., \& Behr, M. (1987). Representations and translations among representations in mathematics learning and problem solving. New Jersey: Lawrence Erlbaum Associates.

[15] Milrad, M. (2002). Using construction kits, modeling tools and system dynamics simulations to support collaborative discovery learning. Educational Technology \& Society, 5(4), 76-87.

[16] Brenner, M. E., Mayer, R. E., Moseley, B., Brar, T., Duran, R., Reed, B. S., \& Webb, D. (1997). Learning by understanding: The role of multiple representations in learning algebra. American Educational Research Journal, 34(4), 663-689.

[17] Spiro, R. J. feltovich, PJ, Jacobson, MJ, and Coulson, RL (1992). Cognitive flexibility, constructivism, and hypertext: random access instruction for advanced knowledge acquisition in ill-structured domain. Constructivism and the technology of instruction: a conversation. Hillside: Lawrence Erlbaum Associates.

[18] Grouws, D. and Meier, S. (1992). Teaching and Assessment Relationships in Mathematics Instruction. In Leder, G. (ed.) Assessment and Learning of Mathematics, Victoria, ACER.

[19] Kozma, R., Chin, E., Russell, J., \& Marx, N. (2000). The roles of representations and tools in the chemistry laboratory and their implications for chemistry learning. The Journal of 
the Learning Sciences, 9(2), 105-143.

[20] Wagner, S. E., \& Kieran, C. E. (1989). Research issues in the learning and teaching of algebra. In This monograph contains revisions of papers presented at The Research Agenda Conference on Algebra, at the University of Georgia, Athens. National Council of Teachers of Mathematics.

[21] Cai \& Lester. (2005). Solution representations and pedagogical representations in Chinese and U. S. classrooms. Journal of Mathematical Behavior, 24(3), 221-237.

[22] Janvier, C. (1987). Representation and understanding: The notion of functions as an example. Dalam C. Janvier (ed.): Problems of Representation in the Teaching and Learning of Mathematics. Hillsdale: Lawrence Erlbaum Associates.

[23] Duval, R. (2006). A cognitive analysis of problems of comprehension in a learning of mathematics. Educational Studies in Mathematics, 61, 103-131.

[24] Bal, A. P. (2015). Skills of using and transform multiple representations of the prospective teachers. Journal of Mathematical Behavior, 197(2015), 582-588.

[25] Seeger, F. (1998). Representations in the mathematics classroom: Reflections and constructions. In F. Seeger, J. Voigt, \& V. Werschescio (Eds.), The culture of the mathematics classroom (pp. 308- 343). Cambridge, UK: Cambridge University Press.

[26] Bossé, M. J., Adu-Gyamfi, K. \& Chandler, K. (2014). Students' differentiated translation processes. International Journal for Mathematics Teaching and Learning. 1-28. Retrieved from http://www.cimt. plymouth.ac.uk/journal/.

[27] Molina, M., Domingo, S. R., Canadas, M. C., \& Castro, E. (2016). Secondary school students' errors in the translation of algelbraic statements. Journal of Science and Math Education, 15(6), 1137-1156.

[28] Rahmawati, D., Purwanto., Subanji., Hidayanto, E., dan Anwar, R. B. (2017). Process of mathematical representation translation from verbal into graphic. International
Electronic Journal of Mathematics Education, 12(3), 367-381.

[29] Nizaruddin, N., Waluyo, St. B., Rochmad \& Isnarto. (2019). Mathematical translation of verbal representation to symbol representation: A case study in prospective teachers having high mathematical ability. Proceeding International conference on Science, Education, and Technology di Universitas Negeri Semarang.

[30] Bartle, R. G., \& Sherbert, D. R. (2000). Introduction to real analysis (Vol. 2). New York: Wiley.

[31] Mills, M. (2014). A framework for example usage in proof presentations. The Journal of Mathematical Behavior, 33, 106-118

[32] Malik, D. S., Mordeson, J. N., \& Sen, M. K. (2007). MTH 581-582: Introduction to Abstract Algebra. United States of America.

[33] Stylianou, D. A., \& Blanton, M. L. (2011). Developing students' capacity for constructing proofs through discourse. Mathematics Teacher, 105(2), 140-145.

[34] Stylianou, D. A., Blanton, M. L., \& Rotou, O. (2015). Undergraduate students' understanding of proof: Relationships between proof conceptions, beliefs, and classroom experiences with learning proof. International Journal of Research in Undergraduate Mathematics Education, 1(1), 91-134.

[35] Thompson, D. R., Senk, S. L., \& Johnson, G. J. (2012) Opportunities to learn reasoning and proof in high school mathematics textbooks. Journal for Research in Mathematics Education, 43(3), 253-295.

[36] Lo, J. J., \& McCrory, R. (2009). Proof and proving in a mathematics course for prospective elementary teachers. ICME Study, 19(2), 41-46.

[37] Yopp, D. A. (2011). How some research mathematicians and statisticians use proof in undergraduate mathematics. The Journal of Mathematical Behavior, 30(2), 115-130. 